\title{
The analysis for time of referral to a medical center among patients with diabetic foot infection
}

\author{
Cheng-Wei Lin ${ }^{1 \dagger}$, Hui-Mei Yang ${ }^{1 \dagger}$, Shih-Yuan Hung ${ }^{1}$, I-Wen Chen ${ }^{1}$ and Yu-Yao Huang ${ }^{1,2,3^{*}}$
}

\begin{abstract}
Background: Diabetic foot infection (DFI) is a limb- and life-threatening complication for diabetic patients needing immediate and comprehensive treatment. Early referral of DFI patients to a diabetic foot center is recommended but there appears limited validated evidence, with the association between referral time and clinical outcomes of limb- preservation or in-hospital mortality still lacking.

Methods: This retrospective research studied consecutive type 2 diabetic patients with DFI treated at the major diabetic foot center in Taiwan from 2014 to 2017. Six hundred and sixty-eight patients presented with limbthreatening DFI. After stratifying their referral days into quartiles, the demographic information and clinical outcomes were analyzed.

Results: One hundred and seventy-two patients were placed in the first quartile (Q1) with less than 9 days of referral time; 164 in the second quartile (Q2) with 9-21 days; 167 in the third quartile (Q3) with 21-59 days; and 165 in the fourth quartile (Q4) with >59 days. End-stage renal disease (ESRD), major adverse cardiac events (MACE) and peripheral arterial disease (PAD) were noted as being higher in the Q4 group compared with the Q1 group (25.45\% vs $20.35 \%$ in ESRD, $47.27 \%$ vs $26.16 \%$ in MACE and $78.79 \%$ vs $52.33 \%$ in PAD respectively). The Q1 group had more patients presenting with systemic inflammatory responsive syndrome (SIRS) (29.07\% in Q1 vs $25.45 \%$ in $\mathrm{Q} 4$ respectively, $P=0.019$ ). Regarding poor outcome (major lower-extremity amputation (LEA) or in-hospital mortality), the Q4 group had 21.21\% of patients in this category and the Q1 group had 10.47\%. The odds ratio of each increased referral day on poor prognosis was 1.006 with $95 \%$ confidence interval $1.003-1.010(P=<0.001)$. In subgroups, the impact on poor prognosis by day was most obvious in patients with SIRS (OR 1.011, 95\% Cl 1.004$1.018, P=0.003)$ and those with PAD (OR 1.004, 95\% Cl 1.001-1.008, $P=0.028)$.
\end{abstract}

Conclusions: The deferred referral of DFI patients to the diabetic foot center might be associated with poor treatment outcome either in major LEA or mortality, particularly in patients with SIRS or PAD. Both physician and patient awareness of disease severity and overcoming the referral barrier is suggested.

Trial registration: Not applicable.

Keywords: Diabetic foot infection, Referral time, Lower-extremity amputation

\footnotetext{
* Correspondence: yyh@cgmh.org.tw

${ }^{\dagger}$ Cheng-Wei Lin and Hui-Mei Yang contributed equally to this work.

'Division of Endocrinology and Metabolism, Chang Gung Memorial Hospital

at Linkou, 5, Fusing St., Guishan Dist, 333 Taoyuan City, Taiwan

${ }^{2}$ College of Medicine, Chang Gung University, Taoyuan City, Taiwan

Full list of author information is available at the end of the article
}

C C The Author(s). 2021 Open Access This article is licensed under a Creative Commons Attribution 4.0 International License, which permits use, sharing, adaptation, distribution and reproduction in any medium or format, as long as you give appropriate credit to the original author(s) and the source, provide a link to the Creative Commons licence, and indicate if changes were made. The images or other third party material in this article are included in the article's Creative Commons licence, unless indicated otherwise in a credit line to the material. If material is not included in the article's Creative Commons licence and your intended use is not permitted by statutory regulation or exceeds the permitted use, you will need to obtain permission directly from the copyright holder. To view a copy of this licence, visit http://creativecommons.org/licenses/by/4.0/ The Creative Commons Public Domain Dedication waiver (http://creativecommons.org/publicdomain/zero/1.0/) applies to the data made available in this article, unless otherwise stated in a credit line to the data. 


\section{Main text \\ Background}

Diabetic foot ulcer (DFU) is the leading cause of nontraumatic lower-extremity amputation (LEA) [1-3]. Early referral of patients with DFU to a specialist multidisciplinary foot team is recommended to prevent limb loss $[4,5]$. In real practice, multiple barriers still exist for patients to reach such services despite current service centers being available and appearing to be functioning relatively well [6-9]. When patients experience DFU, diabetic foot infection (DFI) is the leading threatening problem for limb loss and sepsis $[10,11]$ and is also the most common cause of hospital admissions [1, 3]. Among in-hospital DFU cases, $82 \%$ are reported to have DFIs in Europe and 94\% in Taiwan [12, 13], and the proportion of DFI is still increasing [14]; nevertheless, little data has discussed the association between the referral time and the treatment outcomes of LEA or in-hospital mortality for patients with DFI. This study intended to elucidate the clinical characteristics and outcome associated with the referral time to a diabetic foot center treating patients with DFI.

\section{Materials and Methods}

\section{Subjects and DFI treatments}

Consecutive type 2 diabetic patients with DFI treated at the major diabetic foot center in Taiwan, the Chang Gung Memorial Hospital at Linkou (a 3,700-bed university hospital), were reviewed from 2014 to 2017 as a retrospective research design. In this center, patients received comprehensive foot care from an interdisciplinary team including diabetologists, cardiologists, plastic surgeons, orthopedists, radiologists, dieticians, and nurse practitioners [6-9]. Six hundred and sixty-eight patients presented with limb-threatening DFI (moderate to severe) according to the definition from Infection Disease Society of American (IDSA) [15] and the International Working Group on the Diabetic Foot (IWGDF) [16] criteria. All patients received comprehensive foot care by a multidisciplinary team [6-9]. Empiric antibiotics were prescribed promptly for these patients initially and subsequently modified according to the results of cultures. Surgical interventions, endovascular treatments, or foot amputations were scheduled after the diabetic foot team reached consensus.

\section{Data collection}

The referral days were counted from foot ulcer development to admission. After stratifying referral days into four categories in quartiles, demographic information was recorded from the patients' first visit at admission. Medical records included patient age, gender, diabetes duration, HbA1c level, wound size and medical history such as hypertension, retinopathy, neuropathy and history of major adverse cardiac events (MACEs; including coronary artery disease and cerebrovascular accidents). Smokers were classified as currently smoking if they smoked at least one cigarette per day. End-stage renal disease (ESRD) was defined by chronic renal failure with permanent dialysis therapy. Systemic inflammatory response syndrome (SIRS) was defined when matching two or more of the four criteria including abnormal body temperature $>38^{\circ} \mathrm{C}$ or $<36^{\circ} \mathrm{C}$; tachycardia with pulse $>90$ beat per minute; abnormal respiratory rate with $>20$ breaths per minute; and abnormal leukocyte > 12,000 or $<4000 / \mathrm{cu} \mathrm{mm}$ [15], while peripheral arterial disease (PAD) was defined by non-invasive assessment documentation or symptoms of critical limb ischemia such as cyanosis or gangrene [16].

\section{Prognosis analysis: LEAs and in-hospital mortality}

Status at discharge was stratified into four groups: nonamputation, minor LEA (i.e., amputation performed including digital amputation or tarsal-metatarsal amputation, as long as it did not involve the ankle area), major LEA (i.e., amputation performed above the ankle joint) or in-hospital mortality. Major LEA and in-hospital mortality were defined as poor prognosis while subjects with limb preservation and minor LEA were used for comparison.

\section{Data analysis}

Comparisons of characteristics between patients with quartiles of referral days were performed using the oneway ANOVA test for continuous variables including age, duration of diabetes, wound size, and HbA1c level, while Pearson's chi-square test for categorical variables including gender, smoking status, and comorbidities was used. The odds ratios of each increased referral day correlated with adverse outcome (major LEA or in-hospital mortality) among different comorbidities and severity of DFI were calculated and presented in the forest plot. All statistical analyses were performed using the Statistical Package for the Social Sciences (SPSS for Windows, version 19.0, Armonk, NY: IBM Corp.) software.

\section{Results}

The clinical characteristics among quartiles of referral days in patients with DFI

The comparison of clinical characteristics of subjects between quartiles of referral days of patients with limbthreatening DFI is shown in Table 1. One hundred and seventy-two patients were enrolled in the first quartile with less than 9 days of referral time; 164 in the second quartile with 9-21 days; 167 in the third quartile with 21-59 days; and 165 in the fourth quartile with $>59$ days. The mean age of these patient ranged from 62.96 to 65.19 years without difference and the mean diabetes 
Table 1 Demographics of patients with limb-threatening diabetic foot infection among quartiles of referral time to hospital

\begin{tabular}{|c|c|c|c|c|c|}
\hline & \multicolumn{4}{|c|}{ Days from ulcer to hospital (Quartiles) } & \multirow{2}{*}{$\begin{array}{l}P \\
\text { value }\end{array}$} \\
\hline & $\begin{array}{l}\leq 9 \text { days } \\
(n=172, Q 1)\end{array}$ & $\begin{array}{l}9-21 \text { days } \\
(n=164, Q 2)\end{array}$ & $\begin{array}{l}21-59 \text { days } \\
(n=167, \mathrm{Q} 3)\end{array}$ & $\begin{array}{l}>59 \text { days } \\
(n=165, Q 4)\end{array}$ & \\
\hline Age (years) & $63.85(13.52)$ & $62.96(13.12)$ & $65.62(13.19)$ & $65.19(13.63)$ & 0.244 \\
\hline Gender & & & & & 0.875 \\
\hline Female & $63(36.63 \%)$ & $59(35.98 \%)$ & $64(38.32 \%)$ & $66(40.00 \%)$ & \\
\hline Male & 109 (63.37\%) & $105(64.02 \%)$ & $103(61.68 \%)$ & $99(60.00 \%)$ & \\
\hline Diabetes duration (years) & $12.85(10.04)$ & $13.81(8.90)$ & $14.00(9.67)$ & $15.41(10.04)$ & 0.115 \\
\hline Smoking & $69(40.12 \%)$ & $72(43.90 \%)$ & $69(41.32 \%)$ & $66(40.00 \%)$ & 0.880 \\
\hline Hypertension & $126(73.26 \%)$ & $105(64.02 \%)$ & $117(70.06 \%)$ & 117 (70.91\%) & 0.302 \\
\hline Retinopathy & $88(51.16 \%)$ & $94(57.32 \%)$ & $99(59.28 \%)$ & $97(58.79 \%)$ & 0.405 \\
\hline Neuropathy & $72(41.86 \%)$ & $75(45.73 \%)$ & $85(50.90 \%)$ & $76(46.06 \%)$ & 0.423 \\
\hline End-stage renal disease & $35(20.35 \%)$ & $23(14.02 \%)$ & $24(14.37 \%)$ & $42(25.45 \%)$ & 0.021 \\
\hline Major adverse cardiac event & $45(26.16 \%)$ & $47(28.66 \%)$ & $62(37.13 \%)$ & $78(47.27 \%)$ & $<0.001$ \\
\hline $\mathrm{HbA} 1 \mathrm{c}(\%)$ & $9.21(2.61)$ & $9.47(2.51)$ & $8.84(2.68)$ & $8.50(2.55)$ & 0.008 \\
\hline Wound size $\left(\mathrm{cm}^{2}\right)$ & $30.05(58.27)$ & $45.51(141.00)$ & $21.21(31.57)$ & $38.74(74.88)$ & 0.063 \\
\hline $\mathrm{SIRS}^{\mathrm{a}}$ & $50(29.07 \%)$ & $58(35.37 \%)$ & $34(20.36 \%)$ & $42(25.45 \%)$ & 0.019 \\
\hline Peripheral arterial disease & $90(52.33 \%)$ & $92(56.10 \%)$ & $113(67.66 \%)$ & $130(78.79 \%)$ & $<0.001$ \\
\hline
\end{tabular}

${ }^{\mathrm{a}}$ Systemic inflammatory responsive syndrome

duration was 12.85 years in the earliest referral group and 15.41 years in the latest referral group but with no significance $(P=0.244$ in age and $P=0.115$ in diabetes duration respectively). Male gender predominance was noted in all groups $(60-64.02 \%, P=0.875)$. The proportions of associated comorbidities were high in patients of all four groups, including hypertension around $70 \%$, retinopathy around $57 \%$ and neuropathy around $45 \%$. Of note, the ESRD status, MACE history and presence of PAD were noted as being significantly higher in the latest referral group (fourth quartile, Q4) in comparison with the earliest referral group (first quartile, Q1) (25.45\% vs. $20.35 \%$ in ESRD, $47.27 \%$ vs. $26.16 \%$ in MACE and $78.79 \%$ vs. $52.33 \%$ in PAD respectively) (Table 1; Fig. 1). Regarding symptom presentation, the earliest referral group had more patients presenting with SIRS (29.07\% in Q1 vs. $25.45 \%$ in Q4 respectively, $P=$ $0.019)$, while HbA1c level was also higher in this group (9.21 in Q1 vs. 8.50 in Q4 respectively, $P=0.008$ ).

\section{The association of prognosis and the referral days}

When categorizing the patients into four groups in quartiles of referral days, we found different treatment outcomes (Fig. 2a). For poor treatment outcome, the latest referral group had $21.21 \%$ of patients $(15.15 \%$ major LEA and 6.06\% in-hospital mortality) and the earliest referral group had $10.47 \%$ (8.14\% major LEA and 2.33\% in-hospital mortality). When stratifying the patients according to the comorbidities, the poorest prognosis occurred in the latest referral group, though the trend analysis did not show significance (Fig. 2b). Figure 3 reveals the odds ratios of each day (the interval between foot ulcer to the hospital) contributing to the impact on poor prognosis. For all patients, the odds ratio of each increased referral day on poor prognosis was 1.006 (95\% confidence interval 1.003-1.010, $P<0.001$ ). Regarding the infection severity and comorbidities, the impact on poor prognosis of each increased referral day was most obvious in patients with SIRS (OR 1.011, 95\% CI 1.004$1.018, P=0.003)$ and those with PAD (OR 1.004, 95\% CI 1.001-1.008, $P=0.028)$. The impact was nonsignificantly positive in patients with ESRD (OR 1.004, 95\% CI 0.998-1.010, $P=0.175$ ) and MACE (OR 1.004, 95\% CI 0.999-1.009, $P=0.137$ ). Longer referral days among these DFI patients might have associated with poor treatment outcome either major LEA or in-hospital mortality, particularly in subjects presenting with SIRS or coexisting with PAD.

\section{Discussion}

This study investigated the referral time among patients with limb-threatening DFI and still found barriers on early referral to a diabetic foot center for most patients, even under such serious conditions. More than $25 \%$ of patients took more than two months to admit themselves to the hospital from disease onset. The study also revealed poor prognosis among patients with longer referral time. Major LEA and in-hospital death were defined as poor treatment outcomes and it was found that the latest referral group ( $>59$ days) had more patients 


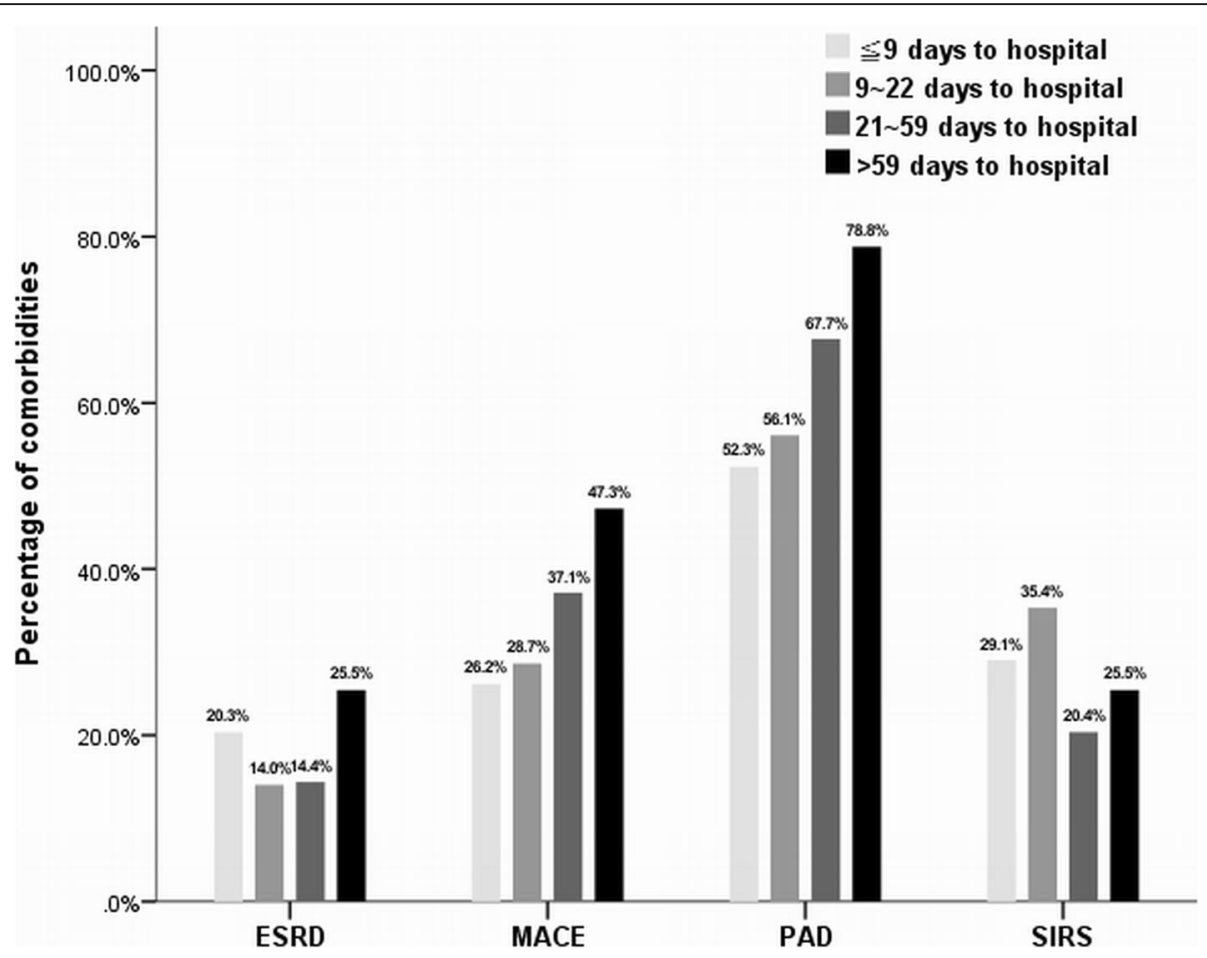

Fig. 1 Proportion of comorbidities in quartiles of referral time to hospitalThe ESRD status, MACE history and presence of PAD were noted as being higher in the latest referral group (fourth quartile) in comparison with the earliest referral group (first quartile) $(25.45 \%$ vs. 20.35\% in ESRD, $47.27 \%$ vs. $26.16 \%$ in MACE and $78.79 \%$ vs. $52.33 \%$ in PAD respectively)

(21.21\%) with poor outcomes (15.15\% major LEA and $6.06 \%$ in-hospital mortality) and the earliest referral group had $10.47 \%$ (8.14\% major LEA and $2.33 \%$ inhospital mortality) of such outcomes (Fig. 2a). The referral barrier was also noted in Europe because of various causes including inconsistent or vague guidelines on management of DFUs, and possible unawareness of the risk among patients and general practitioners $[4,5]$. In the Eurodiale study, duration of ulcer $<1$ week was noted in $17 \%$ of patients; 1 week to 3 months in 58\%; and $>3$ months in $24.9 \%$ [4]. Manu et al. investigated the referral times of patients with diabetic foot ulcers across Europe, and reported $13-24 \%$ of patients had $\geq$ one month between the onset of the wound and the

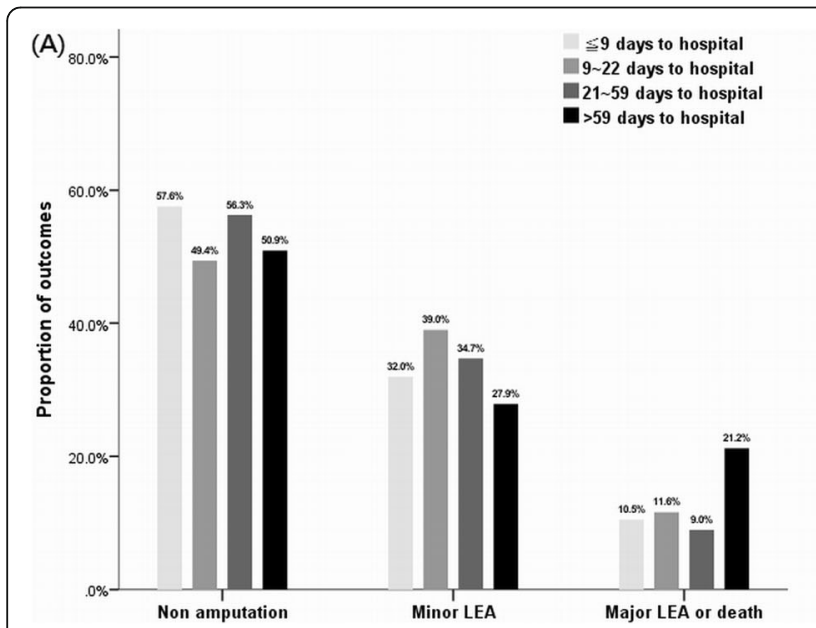

(B)

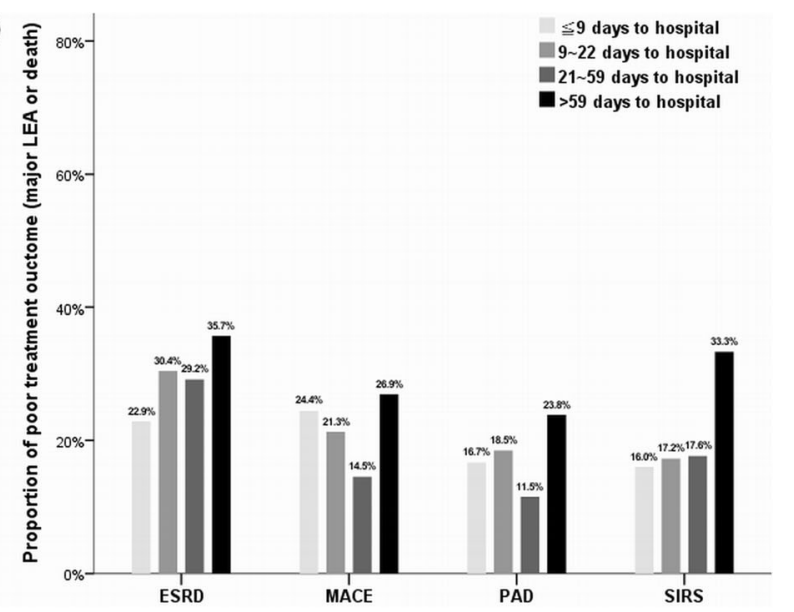

Fig. 2 The outcomes among quartiles of referral time to hospitala The latest referral group had 21.21\% patients resulting in poor outcome (15.15\% major LEA and 6.06\% in-hospital mortality); and the earliest referral group had $10.47 \%$ with poor outcome (8.14\% major LEA and 2.33\% in-hospital mortality). $\mathbf{b}$ For the proportions of poor outcomes (major LEA or mortality) among patients with comorbidities, the poorest prognosis occurred in the latest referral group regardless of comorbidities 


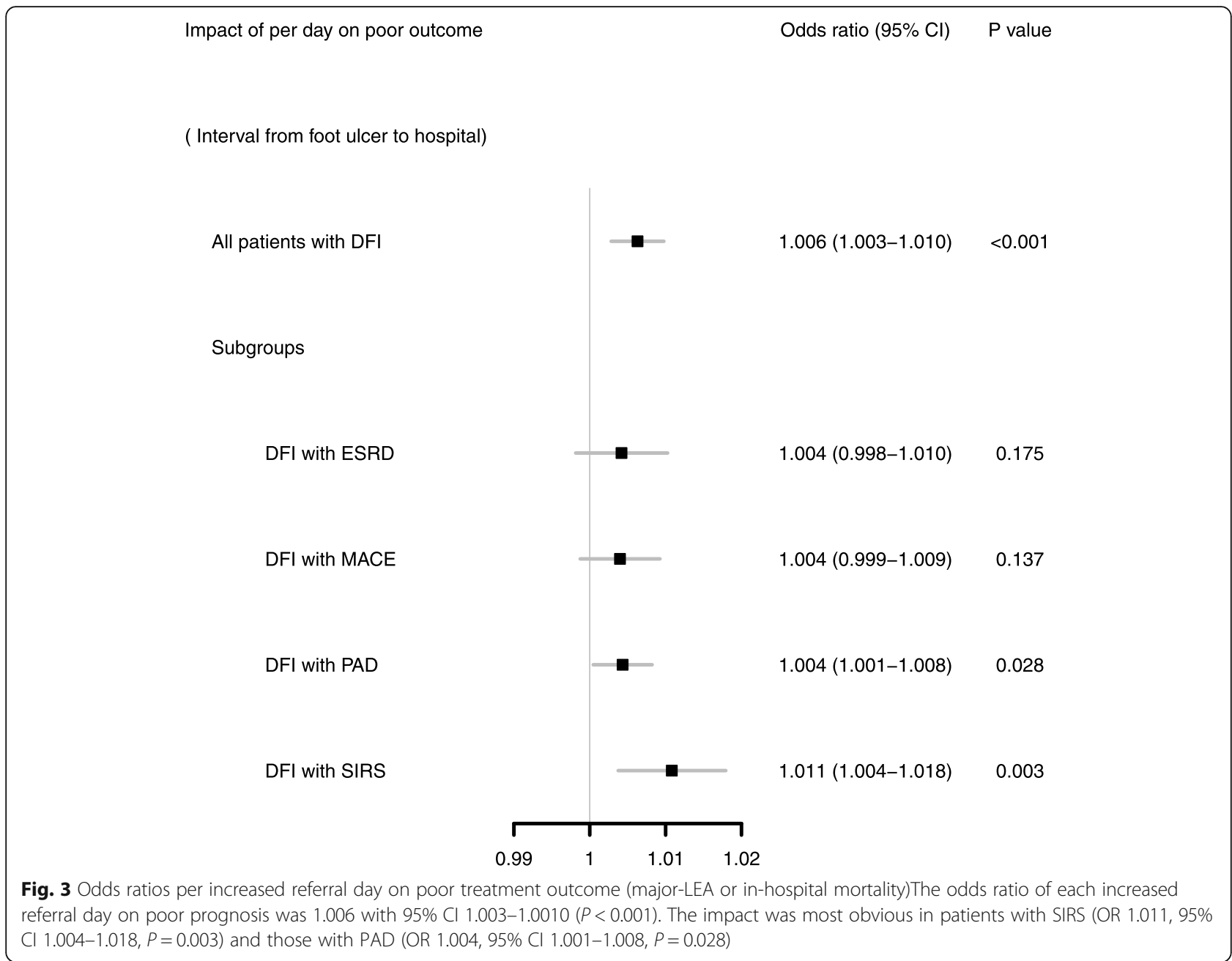

diagnosis of DFU, while 11-22\% were not referred until one or more months after diagnosis. The other two single-center cohort studies revealed patients with a diabetic foot ulcer had a median time between ulcer onset and diagnosis of $4(0-247)$ days (diagnosis delay), and the median time between first review and first referral to the specialist clinic was 15 (0-608) days (referral delay) by Macfarlane and Jeffcoate [17], and 3 days of diagnosis delay with 7 days of referral delay in the study by Antal et al. [18]. In these studies, only Antal et al. investigated the correlation between referral time and clinical outcome and their study suggested healing time was postively correlated to referral time.

This study further disclosed that each increased referral day contributed to the increased poor outcome probability and the tendency was still noted when stratifying the DFI patients according to their comorbidities (Fig. 3). People like these patients with comorbidities are supposed to seek medical help proactively because of their poor health, although surprisingly, in this study, the population coexisting with ESRD, cardiovascular diseases or PAD had a less active attitude to manage their DFI and tended to postpone medical consultations (Fig. 1). Although lacking causal evidence, the reason for the late referral in these patients was supposedly due to the obscureness of the infection symptom by poor perfusion. Both cardiovascular diseases [19, 20] and ESRD [21, 22] are associated with PAD and hence such patients would have poor peripheral perfusion. In theory, poor perfusion is supposed to hinder the symptoms and signs of foot infection by regionalizing the infection only in the foot area, therefore presenting limited inflammation response because of less immune cell reaction [23]. The wound margin tissue necrosis might also develop a barrier to prevent inflammation cytokine dissemination into systemic circulation; consequently, obscure symptoms or signs might lead to unawareness of severity of DFI, particularly in patients with cardiovascular comorbidities. Of note, poorer prognosis was also noted in later referral DFI patients with PAD as well as ESRD or MACE (Fig. 2b). It is known that poor perfusion causes poor tissue oxygen tension and hinders delivery of antibiotics to 
the infected tissue, thereby influencing poor response to treatment [23]; nevertheless, if the poor perfusion is prolonged in the limb, collateral vessel blood supply would no longer be sufficient to compensate for tissue hypoperfusion, which would then result in increased cell loss and ultimately a local inflammatory reaction [24]. Furthermore, inflammation causes injury in tissue and the damaged cells are broken down and replaced by fibrosis, which presents an additional barrier to oxygen diffusion in the tissue thereby further exacerbating ischemia, resulting in a vicious cycle of poorer perfusion, let alone poor limb outcome.

Unlike the comorbidities, the proportions of SIRS presentation were subtly higher in early referral groups but with limited diversity between the different range of referral days (Fig. 1). The presentation of SIRS in patients with DFI always results from more damaged and inflammatory tissue like necrotizing fasciitis, osteomyelitis or abscess formation [9]. SIRS indicates inflammation beyond the infected site traversing throughout the entire body. Such severe infection suggests higher risks to limb loss or mortality, and will almost certainly turn aggressive for DFI treatment once patients experience obvious symptoms such as SIRS. In our study, the similar proportions of SIRS presentation in four groups meant not all DFI patients developed SIRS as soon as disease onset and those with underlying cardiovascular diseases or ESRD might only develop SIRS when infection is advanced. Given previous research, DFI patients would have poor prognosis once they developed SIRS [9]. Our study further documented that despite the same SIRS presentation on arrival, later referral patients still suffered from poorer treatment outcomes. Accordingly, patients and clinicians should recognize the severity of DFI in a timelier manner and patients should be referred to the hospital with a diabetic foot team, even under obscure symptoms.

To grasp time for treatment is important for some diseases to rescue damaged organs. For example, a concept of "time is muscle" was deliberated over by cardiologists regarding the treatment of primary percutaneous coronary intervention for acute ischemic heart disease, aiming to limit the extent of myocardial damage [25, 26], meaning that severity and extent of myocardial ischemic injury resulting from coronary occlusion could be radically altered by timely intervention [26]. A similar thought of "time is limb" was also mentioned in acute limb ischemia needing early recognition of poor perfusion thereby requiring revascularization to prevent limb loss and lifethreatening morbidity $[27,28]$. Beyond limb ischemia, in this study, early referral for early treatment is also supposedly as important for diabetic patients having foot infection, and the analysis revealed the probability of poor outcome (major LEA or death) vis-à-vis each increased referral day. The time impact was more obvious when the patient presented with SIRS or PAD on arrival; therefore, delayed referral to the hospital until severe inflammation or critical limb ischemia has set in should be avoided to prevent limb loss or mortality.

This study was limited by a single center and retrospective design, so it is uncertain whether the correlation between comorbidities and referral time could be applied to the causal factors of delayed referral. The prognosis analysis was according to in-hospital outcomes, and long-term limb preservation and survival require further prospective study designs to be validated.

\section{Conclusions}

Deferred referral to a diabetic foot center for patients with limb-threatening DFI might be associated with poor treatment outcome of either major LEA or in-hospital mortality, particularly in subjects with SIRS or PAD. The awareness of the disease severity of DFI and overcoming the barrier of referral is important for both patients and clinicians, and even obscure symptoms in DFI should not be neglected.

\section{Abbreviations}

DFU: Diabetic foot ulcer; LEA: Lower-extremity amputation; DFI: Diabetic foot infection; IDSA: Infection Disease Society of American; IWGDF: International Working Group on the Diabetic Foot; MACE: Major adverse cardiac event; ESRD: End-stage renal disease; SIRS: Systemic inflammatory response syndrome; PAD: Peripheral arterial disease; OR: Odds ratio; Cl: Confidence interval

\section{Acknowledgements}

The authors thank the staff and participants of these studies for their important contributions.

\section{Authors' contributions}

Conceptualization, YYH; Methodology, CWL; Validation, HMY and CWL; Formal analysis, SYH; Investigation, CWL; Resources, HMY; Data curation, IWC; Writing —original draft preparation, CWL.; Writing —review and editing, YYH; Visualization, CWL; Supervision, YYH; Project administration, YYH; Funding acquisition, $\mathrm{YYH}$. The author(s) read and approved the final manuscript.

\section{Funding}

This study was supported by project grant from the CORPG3J0021. The funders had no role in study design, data collection and analysis, decision to publish, or preparation of the manuscript.

\section{Availability of data and materials}

The datasets used and analyzed during the current study are not publicly available due to the restriction of data access according to the ethics committee but may be available from the corresponding author on reasonable request and with permission of the responsible ethics committee.

Ethics approval and consent to participate

The Institutional Review Board of Chang Gung Medical Foundation approved this study and permitted our access to the data used in our research (IRB No. 201900075B0). The IRB allowed for the exemption of the informed consent of subjects since the study was retrospectively analyzed on anonymized data (National Department of Health Medical Affairs No.1010265083).

Consent for publication

Not applicable. 


\section{Competing interests}

The authors declare that they have no competing interests.

\section{Author details}

'Division of Endocrinology and Metabolism, Chang Gung Memorial Hospital at Linkou, 5, Fusing St., Guishan Dist, 333 Taoyuan City, Taiwan. ${ }^{2}$ College of Medicine, Chang Gung University, Taoyuan City, Taiwan. ${ }^{3}$ Department of Medical Nutrition Therapy, Chang Gung Memorial Hospital, Taoyuan City, Taiwan.

Received: 30 June 2020 Accepted: 27 December 2020

Published online: 09 January 2021

\section{References}

1. Boulton AJM, Vileikyte L, Ragnarson-Tennvall G, Apelqvist J. The global burden of diabetic foot disease. The Lancet. 2005:366:1719-24.

2. Narres M, Kvitkina T, Claessen H, Droste S, Schuster B, Morbach S, Rumenapf G, Van Acker K, Icks A. Incidence of lower extremity amputations in the diabetic compared with the non-diabetic population: A systematic review. PLoS One. 2017;12:e0182081.

3. Prevention CfDCa. National Diabetes Statistics Report. 2017. Atlanta GA. Centers for Disease Control and Prevention, US Dept of Health and Human Services 2017

4. Prompers L, Huijberts M, Apelqvist J, Jude E, Piaggesi A, Bakker K, Edmonds M, Holstein P, Jirkovska A, Mauricio D, et al. Delivery of care to diabetic patients with foot ulcers in daily practice: results of the Eurodiale Study, a prospective cohort study. Diabet Med. 2008;25:700-7.

5. Manu C, Lacopi E, Bouillet B, Vouillarmet J, Ahluwalia R, Ludemann C, Garcia-Klepzig JL, Meloni M, De Buruaga VR, Sanchez-Rios JP, et al. Delayed referral of patients with diabetic foot ulcers across Europe: patterns between primary care and specialised units. J Wound Care. 2018;27:186-92.

6. Lin CW, Hsu LA, Chen CC, Yeh JT, Sun JH, Lin CH, Chen ST, Hsu BR, Huang YY. C-reactive protein as an outcome predictor for percutaneous transluminal angioplasty in diabetic patients with peripheral arterial disease and infected foot ulcers. Diabetes Res Clin Pract. 2010:90:167-72.

7. Hung SY, Huang YY, Hsu LA, Chen CC, Yang HM, Sun JH, Lin CW, Wang CC. Treatment for diabetic foot ulcers complicated by major cardiac events. Can J Diabetes. 2015;39:183-7.

8. Lin CW, Hsu BR, Tsai JS, Yang HM, Lin JR, Lin CH, Huang CH, Hung SY, Huang YY. Effect of limb preservation status and body mass index on the survival of patients with limb-threatening diabetic foot ulcers. J Diabetes Complications. 2017;31:180-5.

9. Lin CW, Hung SY, Huang $\mathrm{CH}$, Yeh JT, Huang YY. Diabetic Foot Infection Presenting Systemic Inflammatory Response Syndrome: A Unique Disorder of Systemic Reaction from Infection of the Most Distal Body. J Clin Med. 2019;8:1538.

10. Armstrong DG, Lipsky BA. Diabetic foot infections: stepwise medical and surgical management. Int Wound J. 2004;1:123-32.

11. Ndosi M, Wright-Hughes A, Brown S, Backhouse M, Lipsky BA, Bhogal M, Reynolds C, Vowden P, Jude EB, Nixon J, Nelson EA. Prognosis of the infected diabetic foot ulcer: a 12-month prospective observational study. Diabet Med. 2018:35:78-88.

12. Prompers L, Huijberts M, Apelqvist J, Jude E, Piaggesi A, Bakker K, Edmonds M, Holstein P, Jirkovska A, Mauricio D, et al. High prevalence of ischaemia, infection and serious comorbidity in patients with diabetic foot disease in Europe. Baseline results from the Eurodiale study. Diabetologia. 2007:50:1825.

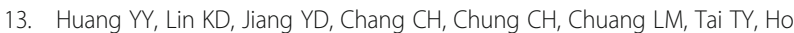
LT, Shin SJ. Diabetes-related kidney, eye, and foot disease in Taiwan: an analysis of the nationwide data for 2000-2009. J Formos Med Assoc. 2012; 111:637-44.

14. Lin CW, Armstrong DG, Lin CH, Liu PH, Hung SY, Lee SR, Huang CH, Huang YY. Nationwide trends in the epidemiology of diabetic foot complications and lower-extremity amputation over an 8-year period. BMJ Open Diabetes Res Care. 2019;7:e000795.

15. Lipsky BA, Berendt AR, Cornia PB, Pile JC, Peters EJ, Armstrong DG, Deery HG, Embil JM, Joseph WS, Karchmer AW, et al. 2012 Infectious Diseases Society of America clinical practice guideline for the diagnosis and treatment of diabetic foot infections. Clin Infect Dis. 2012;54:e132-73.
16. Schaper NC. Diabetic foot ulcer classification system for research purposes: a progress report on criteria for including patients in research studies. Diabetes Metab Res Rev. 2004;20(Suppl 1):90-5.

17. Macfarlane RM, Jeffcoate WJ. Factors contributing to the presentation of diabetic foot ulcers. Diabet Med. 1997;14:867-70.

18. Sanders AP, Stoeldraaijers LG, Pero MW, Hermkes PJ, Carolina RC, Elders PJ. Patient and professional delay in the referral trajectory of patients with diabetic foot ulcers. Diabetes Res Clin Pract. 2013;102:105-11.

19. Peripheral arterial disease. in people with diabetes. Diabetes Care. 2003;26: 3333-41.

20. Gerhard-Herman MD, Gornik HL, Barrett C, Barshes NR, Corriere MA, Drachman DE, Fleisher LA, Fowkes FG, Hamburg NM, Kinlay S, et al. 2016 AHA/ACC Guideline on the Management of Patients With Lower Extremity Peripheral Artery Disease: Executive Summary: A Report of the American College of Cardiology/American Heart Association Task Force on Clinical Practice Guidelines. Circulation. 2017;135:e686-725.

21. O'Hare A, Johansen K. Lower-extremity peripheral arterial disease among patients with end-stage renal disease. J Am Soc Nephrol. 2001;12:2838-47.

22. Rajagopalan S, Dellegrottaglie S, Furniss AL, Gillespie BW, Satayathum S, Lameire N, Saito A, Akiba T, Jadoul M, Ginsberg N, et al. Peripheral arterial disease in patients with end-stage renal disease: observations from the Dialysis Outcomes and Practice Patterns Study (DOPPS). Circulation. 2006; 114:1914-22.

23. Fry DE, Marek JM, Langsfeld $M$. Infection in the ischemic lower extremity. Surg Clin North Am. 1998;78:465-79.

24. Simon F, Oberhuber A, Floros N, Duppers P, Schelzig H, Duran M. Pathophysiology of chronic limb ischemia. Gefasschirurgie. 2018;23:13-8.

25. De Luca G, van 't Hof AW, de Boer MJ, Ottervanger JP, Hoorntje JC, Gosselink AT, Dambrink JH, Zijlstra F, Suryapranata H. Time-to-treatment significantly affects the extent of ST-segment resolution and myocardial blush in patients with acute myocardial infarction treated by primary angioplasty. Eur Heart J. 2004;25:1009-13.

26. Abreu LM. Time is Muscle. Arq Bras Cardiol. 2019;112:408-9.

27. Shishehbor $\mathrm{MH}$. Acute and critical limb ischemia: when time is limb. Cleve Clin J Med. 2014;81:209-16.

28. Obara H, Matsubara K, Kitagawa Y. Acute Limb Ischemia. Ann Vasc Dis. 2018 11:443-8

\section{Publisher's Note}

Springer Nature remains neutral with regard to jurisdictional claims in published maps and institutional affiliations.

Ready to submit your research? Choose BMC and benefit from:

- fast, convenient online submission

- thorough peer review by experienced researchers in your field

- rapid publication on acceptance

- support for research data, including large and complex data types

- gold Open Access which fosters wider collaboration and increased citations

- maximum visibility for your research: over $100 \mathrm{M}$ website views per year

At $\mathrm{BMC}$, research is always in progress.

Learn more biomedcentral.com/submission 